\title{
A influência do tipo de cimento no desempenho de concretos avançados formulados a partir do método de dosagem computacional
}

\section{(The influence of cement type on the performance of advanced concretes designed by computing mix proportion technique)}

\author{
A. L. de Castro ${ }^{1}$, J.B. L. Liborio ${ }^{2}$, V. C.Pandolfelli ${ }^{1}$ \\ ${ }^{I}$ Departamento de Engenharia de Materiais, Universidade Federal de S. Carlos, Rod. Washington Luiz, km 235, \\ S. Carlos, SP 13565-905 \\ ${ }^{2}$ Escola de Engenharia de S. Carlos, Universidade de S. Paulo, Av. Trabalhador Sancarlense 400, \\ S. Carlos, SP 13566-590 \\ alelorencastro@yahoo.com.br,vicpando@power.ufscar.br
}

\begin{abstract}
Resumo
Ao se produzir uma mistura de concreto, especialmente de alto desempenho, a primeira escolha a ser feita é quanto ao tipo de cimento a ser empregado, o que faz deste ligante um material essencial para a produção desses materiais. As características reológicas de formulações de concretos de alto desempenho estão relacionadas com a hidratação dos aluminatos do cimento, enquanto o desenvolvimento da resistência mecânica é dependente dos silicatos hidratados formados. Assim, variações nas características do cimento influenciam as propriedades dos concretos, sendo observados comportamentos distintos para misturas produzidas com diferentes cimentos. O presente artigo visa avaliar a influência do tipo de cimento sobre o desempenho de concretos especiais aplicados na construção civil, dosados a partir de um método computacional. As propriedades no estado fresco foram avaliadas medindo-se o índice de fluidez e determinando-se o comportamento reológico do material. No estado endurecido, a resistência mecânica foi avaliada pelos ensaios de compressão uniaxial, tração por compressão diametral e flexão em 3 pontos, enquanto o módulo de elasticidade foi avaliado pelos métodos estático e dinâmico. Comparando-se todas as propriedades medidas, verifica-se que os concretos produzidos com cimento Portland apresentaram desempenhos superiores ao do concreto produzido com cimento aluminoso, sendo o cimento Portland de alta resistência inicial ainda mais eficiente que o cimento Portland composto com escória para a produção de misturas de alto desempenho e até os 28 dias de idade.

Palavras-chave: concreto de alto desempenho, cimento, propriedade reológica, resistência mecânica.
\end{abstract}

Abstract

When a concrete is produced, especially a high performance one, the first concern is the cement type to be used, making this binder an essential compound. The rheological properties of high performance concretes are related to the hydration of cement aluminates phase, whereas the development of mechanical strength depends on the hydrated silicates formed. Thus, variations on cement characteristics influence the properties of a concrete, being observed different behaviors for mixtures produced with distinct cements. The present paper aims to evaluate the influence of cement type on the performance of special concretes designed using computing techniques. The fresh properties were evaluated measuring the fluidity index and the rheological behavior of the material. In the hardened condition, the mechanical strength were evaluated by the compressive, splitting tensile and 3 point bending tests, whereas the Young's modulus was measured by the static and dynamic methods. By comparing all the measured properties, the concretes produced with Portland cement showed better performance than that containing calcium aluminate cement, being the high early strength Portland cement more efficient than the slag-modified Portland cement for the production of high performance mixtures and until the age of 28 days.

Keywords: high performance concrete, cement, rheological property, mechanical resistance.

\section{INTRODUÇÃO}

Os concretos atuais são mais do que uma simples mistura de cimento, água e agregados. Normalmente contêm adições minerais e aditivos químicos que conferem propriedades especiais, ou ainda, corrigem certas deficiências do cimento usado. O desenvolvimento de novos concretos não resulta necessariamente no aumento da disponibilidade de novos tipos de cimento, mas necessita que a qualidade deste seja reprodutível, atendendo a especificações muito mais severas [1]. Ao se produzir uma mistura de concreto, especialmente de alto desempenho, a primeira escolha a ser feita é quanto ao tipo de cimento a ser empregado, isto porque seu desempenho em termos de reologia e de comportamento mecânico torna-se um item crítico à medida que a resistência à compressão desejada aumenta [2]. Assim, o cimento 
ainda é um material essencial para a produção do concreto. Atualmente, a partir de um cimento comercialmente disponível, é possível obter um novo aglomerante hidráulico com características específicas para uma determinada utilização. Esse novo material pode ser composto com diversos constituintes, tais como clínquer, gipsita, escória de alto-forno, cinza volante, sílica ativa de ferro-silício ou silício metálico, cinza e sílica extraídas da casca de arroz, metacaulinita, terras diatomáceas, argilas calcinadas, pós de concreto reciclado, cerâmica moída, vidros, microfibras, fíler calcário etc. [3]. Assim, com a utilização de uma menor quantidade de clínquer, a indústria do cimento atinge alguns de seus objetivos dentro da perspectiva do desenvolvimento sustentável. Os diferentes tipos de cimento existentes não apresentam o mesmo desempenho quando se produz um concreto de alto desempenho. Alguns possuem um bom desempenho em termos de resistência mecânica, mas um inadequado comportamento reológico, o que dificulta o lançamento e o adensamento do material; outros apresentam um ótimo comportamento reológico, porém seu desempenho mecânico deixa a desejar. Assim, devido à grande variabilidade nas propriedades físicas e químicas do cimento, deve-se esperar que diferentes cimentos se comportem de maneiras distintas na presença de um mesmo aditivo (indispensável para a produção de misturas de alto desempenho).

As características reológicas de traços com baixa relação água/aglomerante (concretos de alto desempenho) estão relacionadas com a hidratação dos aluminatos do cimento (fase intersticial), enquanto o desenvolvimento da resistência mecânica é dependente dos silicatos hidratados formados. Sendo assim, o desempenho final do cimento na produção dessas misturas dependerá da maneira pela qual o comportamento reológico e o desenvolvimento da resistência podem ser simultaneamente otimizados [2].

Influência do cimento sobre as propriedades do concreto no estado fresco

Diversos fatores influenciam a reologia de materiais à base cimento, tais como a relação água/cimento, a composição química e o tempo de hidratação do cimento, a reatividade química do fíler, a distribuição granulométrica, a massa específica, a textura superficial e a geometria das partículas, as propriedades do aditivo químico, a temperatura e a umidade do meio onde o material é preparado e aplicado, as condições de mistura e o procedimento de ensaio adotado [4]. Assim, existem diversos fatores a serem considerados, sendo a situação ainda mais complicada pelo fato da existência de interações físico-químicas entre eles. No caso específico do cimento, dentre suas características físicas, a área superficial e a distribuição granulométrica são as mais importantes em termos de fluidez da mistura [5]. Dentre os parâmetros químicos, aqueles que têm exercido maior influência sobre as propriedades das misturas são a perda ao fogo, o teor e a morfologia do $\mathrm{C}_{3} \mathrm{~A}$, o teor de álcalis e o tipo de sulfato de cálcio adicionado ao clínquer [6]. Assim, o cimento não pode ser considerado como um material cujo comportamento pode ser previsto por uma única variável. Além disso, no caso dos concretos de alto desempenho, a reologia não é mais ditada apenas pela quantidade de água ou pela forma do agregado graúdo, mas sim pelo que hoje é conhecido como compatibilidade entre o cimento e o aditivo usados [1]. O fator chave que controla o comportamento de um superplastificante é a composição do cimento (tipo de clínquer e produtos de hidratação), uma vez que o efeito positivo do aditivo só é verificado se ele melhorar as propriedades do concreto pela reação com os produtos da hidratação do cimento. Isso pode ocorrer tanto pelos efeitos de desaglomeração e dispersão das partículas de cimento quanto pela influência sobre as taxas de reação do $\mathrm{C}_{3} \mathrm{~A}$ e do $\mathrm{C}_{3} \mathrm{~S}$, constituintes do cimento $[7,8]$.

\section{Influência do cimento sobre as propriedades do concreto} no estado endurecido

Como a reatividade dos componentes minerais do cimento com a água varia consideravelmente, é possível modificar as características de desenvolvimento da resistência de materiais contendo este ligante hidráulico pela simples alteração das proporções dos componentes do cimento. Por exemplo, no caso do cimento Portland, as resistências iniciais (aos 3, 7 e 28 dias) serão altas se o cimento contiver grandes quantidades de $\mathrm{C}_{3} \mathrm{~S}$ e $\mathrm{C}_{3} \mathrm{~A}$, enquanto essas serão baixas se o cimento for composto por uma proporção elevada de $\mathrm{C}_{2} \mathrm{~S}$. Adicionalmente, a resistência final (em idades mais avançadas) de um cimento rico em $\mathrm{C}_{2} \mathrm{~S}$ deverá ser maior do que a de outro cimento com baixo teor desse componente mineral [9]. Além da composição do cimento, as taxas de desenvolvimento de resistência podem ser prontamente controladas por meio da adequação da granulometria (área superficial) desse material. Para uma determinada relação água/cimento, a redução do tamanho médio das partículas geralmente resulta em uma maior taxa de hidratação e, assim, em melhores propriedades e maiores resistências nas primeiras idades. Porém, do ponto de vista da durabilidade, cimentos com área superficial superior nem sempre são preferidos; em concretos de alto desempenho, cimentos com granulometria mais grossa podem oferecer desempenho equivalente aos cimentos mais finos a longo prazo, resultando em economia de energia e recursos devido à redução do tempo de moagem [10]. As propriedades de um material à base de cimento estão relacionadas com sua porosidade, a qual depende da densidade de empacotamento das partículas e do grau de hidratação do cimento, porém as influências de ambos os parâmetros são opostas: para uma distribuição granulométrica mais aberta, a densidade de empacotamento é maior, enquanto o grau de hidratação é menor; para uma distribuição granulométrica mais estreita, a densidade de empacotamento é menor, mas o grau de hidratação é maior, desde que o tamanho das partículas do cimento seja pequeno. Assim, as duas situações devem ser consideradas simultaneamente a fim de ser obter a menor porosidade possível: nas primeiras idades, o efeito do 
empacotamento sobre a porosidade é principal, enquanto o efeito do grau de hidratação é secundário; em idades mais avançadas, os efeitos de ambos os fatores influenciam a porosidade em uma mesma extensão [11]. No período de cura, o processo de hidratação resulta na redução e na redistribuição do sistema de poros ativos determinado pela relação água/cimento da mistura; assim, a forma e o tamanho desses poros são influenciados pela entrada e saída de umidade no interior do concreto. A porosidade ativa, consistindo de capilares e poros de gel, pode ser descrita como canais longos e contínuos quando comparada com a forma (aproximadamente) circular e natureza discreta dos poros inativos (originados pela incorporação ou aprisionamento de ar na mistura). A resistência mecânica e o módulo de elasticidade são reduzidos proporcionalmente com o volume de poros inativos e são influenciados pelo volume de poros ativos e pela umidade dentro deles [12].

\section{Objetivos}

A partir da revisão bibliográfica apresentada, é possível constatar que as características do cimento influenciam diretamente as propriedades dos concretos, podendo ser observados comportamentos diferenciados para misturas produzidas com cimentos distintos. Assim, o presente artigo tem como objetivo avaliar a influência do tipo de cimento sobre o desempenho de concretos especiais aplicados na construção civil, dosados a partir de um método computacional, por meio da determinação das propriedades tanto no estado fresco (índice de fluidez e reologia) quanto no estado endurecido (resistência mecânica e módulo de elasticidade).

\section{MATERIAIS E MÉTODOS}

\section{Materiais}

Para verificar a influência do cimento sobre o comportamento de concretos de alto desempenho, três cimentos distintos foram utilizados: cimento Portland de alta resistência inicial (CPV ARI), cimento Portland composto com escória (CPII E 32) e cimento aluminoso (Secar 71). As composições químicas, bem como as composições potenciais são apresentadas na Tabela I. As propriedades físicas desses cimentos são apresentadas na Tabela II e a distribuição granulométrica na Fig. 1.

Quatro agregados - com distribuições granulométricas distintas e controladas - foram utilizados na composição dos concretos: AG 10-20, AG 05-08, AG 40-50 e AG 80-100 (todos fornecidos pela Mineração Jundu). Todos eles são areias de origem quartzosa, constituídos por grãos arredondados. A granulometria é controlada por meio de técnicas estatísticas de tamanho efetivo e coeficiente de uniformidade, enquanto as características físicas e químicas são mantidas estáveis e em conformidade com as especificações de mercado (especialmente de filtros, vidros e cerâmicas).

Pós de quartzo - SM 200, SM 400 e SM 500 - também
Tabela I - Composições química e potencial dos cimentos utilizados.

[Table I - Chemical and potential phase compositions of the used cements.]

\begin{tabular}{|c|c|c|c|}
\hline \multirow{2}{*}{ Óxidos } & \multicolumn{3}{|c|}{ Resultado (\%) } \\
\hline & CPV ARI & CPII E 32 & Secar $71^{(1)}$ \\
\hline $\mathrm{SiO}_{2}$ & 21,16 & 21,86 & $<0,80$ \\
\hline $\mathrm{Al}_{2} \mathrm{O}_{3}$ & 4,71 & 4,96 & $\geq 68,50$ \\
\hline $\mathrm{Fe}_{2} \mathrm{O}_{3}$ & 1,89 & 1,83 & $<0,30$ \\
\hline $\mathrm{CaO}$ & 68,08 & 63,57 & $\geq 31,00$ \\
\hline $\mathrm{SO}_{3}$ & 2,77 & 1,78 & $<0,30$ \\
\hline $\mathrm{MgO}$ & 0,48 & 1,46 & $<0,50$ \\
\hline $\mathrm{TiO}_{2}$ & 0,15 & 0,16 & $<0,25$ \\
\hline $\begin{array}{c}\text { Alcalis }\left(\mathrm{Na}_{2} \mathrm{O}\right. \\
\text { equivalente })\end{array}$ & 0,65 & 0,67 & ----- \\
\hline $\mathrm{K}_{2} \mathrm{O}+\mathrm{Na}_{2} \mathrm{O}$ solúvel & ----- & ----- & $<0,50$ \\
\hline Perda ao fogo & 2,39 & 4,98 & ----- \\
\hline \multicolumn{4}{|c|}{ Composição potencial (\%) } \\
\hline $\mathrm{C}_{3} \mathrm{~S}^{(2)}$ & 74,10 & 51,65 & ----- \\
\hline $\mathrm{C}_{2} \mathrm{~S}^{(2)}$ & 4,77 & 23,71 & ----- \\
\hline $\mathrm{C}_{3} \mathrm{~A}^{(2)}$ & 9,28 & 10,05 & ----- \\
\hline $\mathrm{C}_{4} \mathrm{AF}^{(2)}$ & 5,75 & 5,57 & ----- \\
\hline CA & ----- & ----- & 40 a 70 \\
\hline $\mathrm{CA}_{2}$ & ----- & ----- & $<25$ \\
\hline $\mathrm{C}_{12} \mathrm{~A}_{7}$ & ----- & ----- & $<3$ \\
\hline
\end{tabular}

(I) Os dados da composição química do Secar 71 foram fornecidos pelo fabricante (Kerneos, 2008); (2) Determinada a partir das equações de Bogue.

Tabela II - Propriedades físicas dos cimentos utilizados. [Table II - Physical properties of the used cements.]

\begin{tabular}{cccc}
\hline Propriedades físicas & CPV & CPII E & Secar \\
& ARI & 32 & 71 \\
\hline Massa específica $\left(\mathrm{g} / \mathrm{cm}^{3}\right)$ & 3,16 & 3,11 & 3,00 \\
Área superficial - B.E.T. $\left(\mathrm{m}^{2} / \mathrm{g}\right)$ & 1,70 & 0,64 & 2,16 \\
Início de pega $(\mathrm{min})^{(1)}$ & 143 & 232 & 279 \\
Fim de pega $(\mathrm{min})^{(1)}$ & 338 & 397 & 414 \\
Teor de água de & & & \\
consistência normal (a/c) & 0,30 & 0,28 & 0,28 \\
Resistência à compressão $(\mathrm{MPa})$ & & & \\
1 dia & 25,2 & 5,6 & 39,0 \\
3 dias & 36,2 & 19,5 & 51,8 \\
7 dias & 39,8 & 28,1 & 54,7 \\
28 dias & 47,4 & 37,4 & 60,9 \\
\hline
\end{tabular}

(1) Os tempos de início e fim de pega foram medidos pela agulha de Vicat.

foram utilizados na composição dos concretos. Esses pós são sílicas moídas obtidos a partir de matérias-primas de qualidade superior. Esses materiais são disponíveis em granulometrias variadas e comercializados pela Mineração Jundu para a 


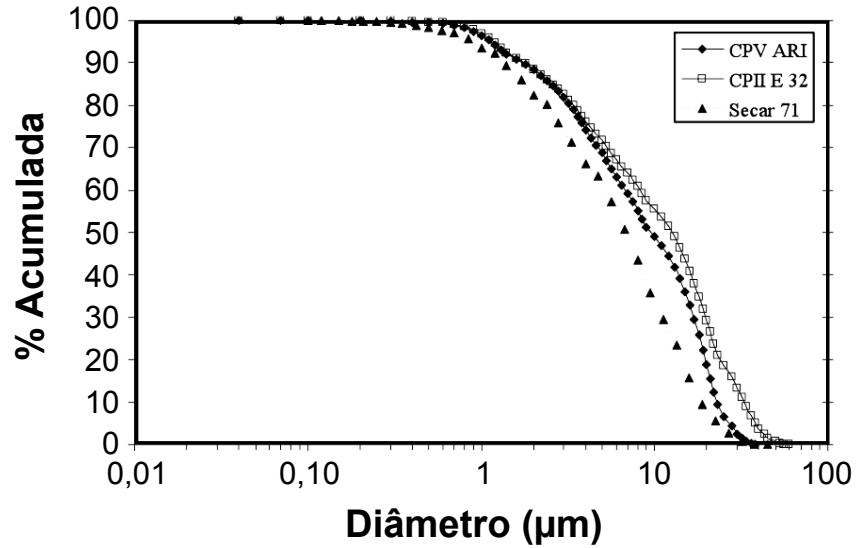

Figura 1: Distribuição granulométrica dos cimentos utilizados. [Figure 1: Particle size distribution of the cements used.]

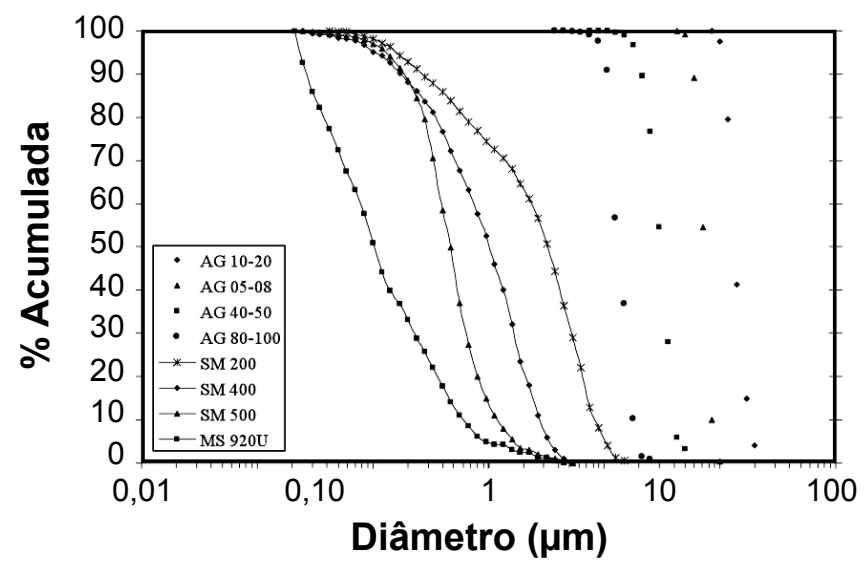

Figura 2: Distribuição granulométrica dos agregados e dos materiais finos utilizados.

[Figure 2: Particle size distribution of the aggregates and fine materials used.]

produção de tintas, plásticos, borrachas, esmaltes, abrasivos etc.

A sílica MS 920U utilizada como adição mineral nos concretos é uma sílica ativa não-densificada obtida a partir da fabricação de silício metálico ou de ligas de ferrosilício, fornecida pela Elkem. É um material extremamente fino, constituído de pequenas partículas esféricas com diâmetros médios de cerca de 50 a 100 vezes menores que os das partículas de cimento $(\sim 100 \%<1 \mu \mathrm{m})$, resultando em uma área superficial específica elevada $\left(\sim 20 \mathrm{~m}^{2} / \mathrm{g}\right)$. A sílica apresenta uma composição química consistente, sendo qualificada como quase pura, uma vez que suas partículas possuem altos teores de sílica amorfa ( $>98 \%$ de $\mathrm{SiO}_{2}$ ) quando comparado à presença de pequenas quantidades de outros elementos.

A distribuição granulométrica dos agregados e dos materiais finos que compõem os concretos estudados é apresentada na Fig. 2.

\section{Composições dos concretos}

Os modelos de empacotamento de partículas podem fornecer ferramentas para melhorar o desempenho de um concreto pela redução do teor de água livre e aumento da quantidade de sólidos. Eles permitem determinar a combinação ótima dos constituintes da mistura a fim de obter máxima densidade de empacotamento e, com isso, minimizar a quantidade de vazios. Esses métodos de dosagem adotam um dos diversos modelos matemáticos disponíveis e, a partir das características físicas dos materiais constituintes são feitas distintas combinações entre eles até se atingir a condição ótima, dada em termos de porosidade e permeabilidade mínimas, abatimento e resistência à compressão máximos [13].

O estudo do empacotamento do sistema granular dos concretos foi feito a partir do modelo de Alfred, com coeficiente de distribuição $(q)$ igual a 0,26 . As curvas de distribuição granulométrica (Fig. 3) dos concretos foram semelhantes para os três tipos de cimento usados, verificando-se pequenas variações entre os coeficientes de correlação obtidos para cada composição.

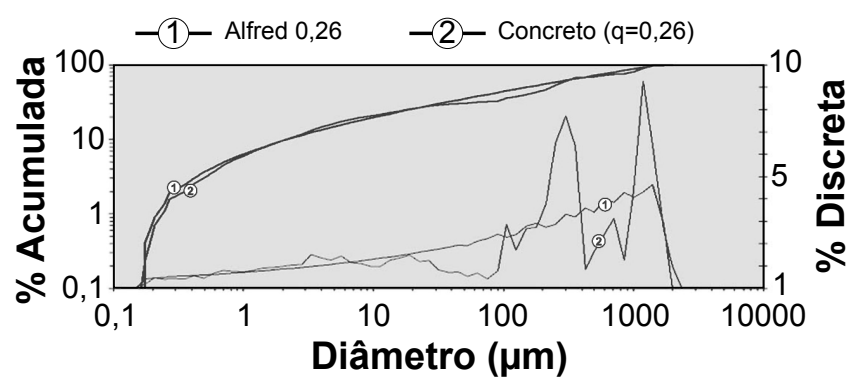

Figura 3: Curva da distribuição granulométrica dos concretos estudados.

[Figure 3: Particle size distribution of the concretes analyzed.]

As proporções das matérias-primas constituintes dos concretos foram iguais para todos os cimentos usados, sendo os valores obtidos apresentados na Tabela III. A quantidade de água de mistura foi mantida fixa em $7 \% \mathrm{em}$ peso (correspondendo a uma relação água/aglomerante igual a 0,35 ) para todas as composições, enquanto os teores de aditivo foram determinados a fim de se obter misturas

Tabela III - Proporção entre as matérias-primas dos concretos estudados.

[Table III - Raw materials content for the concretes analyzed.]

\begin{tabular}{c|c}
\hline Matéria-prima & $\% \mathrm{p}$ \\
\hline AG 10-20 & 24,0 \\
AG 05-08 & 7,0 \\
AG 40-50 & 29,0 \\
AG 80-100 & 7,5 \\
SM 200 & 7,0 \\
SM 400 & 3,0 \\
SM 500 & 2,5 \\
MS 920U & 10,0 \\
Cimento & 10,0 \\
\hline
\end{tabular}


auto-adensáveis (índice de fluidez livre maior ou igual a $80 \%$ ) - os teores utilizados para os concretos compostos com CPV ARI, CPII E 32 e Secar 71 foram iguais a $0,65 \%$, $0,50 \%$ e $0,60 \%$, respectivamente, obtendo-se índices de fluidez iguais a $89 \%, 80 \%$ e $83 \%$. Vale lembrar que as quantidades de água e superplastificante são determinadas para a quantidade total de material e não apenas sobre a quantidade de cimento e/ou aglomerante (cimento e sílica ativa) e que a quantidade de água presente no superplastificante foi descontada da água de mistura.

\section{PROCEDIMENTO EXPERIMENTAL}

O procedimento experimental constituiu na definição dos traços de concreto a partir de um método de dosagem computacional, com posterior avaliação de suas propriedades tanto no estado fresco quanto no estado endurecido.

A definição dos traços foi dividida em duas etapas: empacotamento do sistema granular e determinação do teor ótimo de superplastificante. O empacotamento do sistema granular foi elaborado utilizando o modelo de Alfred, com coeficiente de distribuição igual a 0,26 . O teor ótimo de aditivo foi definido como aquele que possibilitou atingir índice de fluidez de um concreto auto-adensável, ou seja, maior que $80 \%$ de fluidez livre.

$\mathrm{O}$ procedimento adotado na mistura dos concretos envolveu a homogeneização do material seco em sacos plásticos, sendo em seguida a água adicionada e o material misturado em um reômetro por 1 min na velocidade de rotação de $20 \mathrm{rpm}$. O superplastificante foi adicionado após esse período e a velocidade de rotação do reômetro foi aumentada para $60 \mathrm{rpm}$, totalizando o tempo de mistura em 6 min.

A avaliação das propriedades no estado fresco compreendeu a medida do índice de fluidez da mistura e a determinação de suas propriedades reológicas. Para a medida do índice de fluidez, uma amostra de concreto foi colocada em um molde tronco-cônico metálico - com diâmetro superior de $70 \mathrm{~mm}$, diâmetro inferior de $100 \mathrm{~mm}$ e altura de $65 \mathrm{~mm}-\mathrm{e}$, após corretamente nivelado, foi retirado verticalmente. Dois diâmetros ortogonais da amostra foram medidos e o índice de fluidez determinado pela equação A.

$$
\text { Fluidez }=100\left[\frac{\left(D_{\text {esp }}-D_{\text {inf }}\right)}{D_{\text {inf }}}\right]
$$

onde $\mathrm{D}_{\text {esp }}$ é o diâmetro médio do espalhamento $[\mathrm{cm}]$ e $\mathrm{D}_{\text {inf }}=$ diâmetro inferior do molde tronco-cônico [cm].

As propriedades reológicas dos concretos foram determinadas com o auxílio de um reômetro. Para a caracterização reológica (identificação do comportamento reológico), amostras de concreto foram submetidas a ciclos de cisalhamento em escada, com velocidade de rotação variando entre $5 \mathrm{rpm}$ e $80 \mathrm{rpm}$ após a mistura. As curvas de cisalhamento obtidas foram ajustadas por dois modelos reológicos - Bingham e Lei das potências, sendo o comportamento reológico identificado pelo modelo que melhor se ajustou à curva de cisalhamento, ou seja, aquele que permitiu obter o maior coeficiente de correlação entre os dados obtidos pelo reômetro e a reta constitutiva do modelo reológico. Além disso, as curvas de mistura dos concretos foram geradas e a energia de mistura foi determinada como a área sob a curva do torque versus tempo. Assim, foi possível verificar a eficiência desta etapa para cada composição. O acompanhamento das propriedades reológicas foi feito por um intervalo de até uma hora após o contato água-cimento; assim, foi possível verificar a perda de trabalhabilidade e das demais propriedades por meio da evolução dos parâmetros reológicos - tensão de escoamento e viscosidade plástica. $\mathrm{O}$ processo de endurecimento das misturas também foi acompanhado pelo ensaio de cisalhamento contínuo (sob velocidade de rotação constante) durante o período compreendido desde o fim da mistura até a total perda de trabalhabilidade do material (falta de coesão da amostra).

Ensaios de condutividade iônica, em função do tempo, também foram realizados a fim de verificar o comportamento da hidratação dos cimentos utilizados na composição dos concretos estudados. Os ensaios foram realizados em suspensões aquosas de cimento, preparadas com um teor de sólidos de $8,4 \%$ em volume.

A avaliação das propriedades no estado endurecido compreendeu a medida da porosidade aparente, da resistência mecânica e do módulo de elasticidade. A relação completa dos ensaios realizados, bem como os métodos de ensaio adotados, é apresentada a seguir: porosidade aparente [14]; resistência à compressão uniaxial de corpos de prova cilíndricos [15]; resistência à tração por compressão diametral de corpos de prova cilíndricos [16]; resistência à flexão em três pontos de corpos de prova prismáticos [17]; módulo de elasticidade estático em corpos de prova cilíndricos [18]; módulo de elasticidade dinâmico em corpos de prova prismáticos [19]. Para isso, corpos de prova cilíndricos e prismáticos foram moldados em dimensões de $40 \mathrm{~mm} \mathrm{x}$ $40 \mathrm{~mm}$ e $25 \mathrm{~mm}$ x $25 \mathrm{~mm} \times 150 \mathrm{~mm}$, respectivamente. O método de cura adotado foi a úmido por imersão em água saturada com cal, onde os corpos de prova permaneceram até as idades de ensaio: 1, 3, 7 11, 15, 19, 23 e 28 dias para o CPV ARI e o CPII E 32 e 1, 3, 5, 7 e 10 dias para o Secar 71. Para os ensaios de resistência à compressão uniaxial e módulo de elasticidade estático, as superfícies dos corpos de prova cilíndricos foram retificadas.

\section{RESULTADOS E DISCUSSÃO}

\section{Propriedades do concreto no estado fresco}

\section{Curvas de mistura}

A avaliação do desempenho de um concreto começa com a compreensão das suas características e do equipamento utilizado em sua produção. Na etapa de produção do concreto, dois itens são importantes: a composição da mistura e o 
procedimento de mistura do concreto. A qualidade de uma mistura é influenciada por diversos parâmetros associados com o misturador e com sua utilização, tais como a velocidade, o tempo, o volume de material e a geometria dos elementos de mistura. Um parâmetro básico importante de um misturador de concreto é sua velocidade máxima, que depende da resistência da partícula e do comportamento do material a ser misturado. Assim, uma mistura idealé obtida quando todos os componentes estão distribuídos uniformemente na massa da mistura, isto é, cada amostra retirada do misturador deve apresentar as mesmas características [20]. Para um mesmo procedimento de mistura, verificou-se que a variação do tipo de cimento implicou em alterações da área sob a curva de mistura das composições (Fig. 4, Tabela IV). Como uma menor área indica uma melhor dispersão das partículas e, conseqüentemente, em uma mistura mais efetiva, o procedimento de mistura adotado foi mais eficiente para os concretos produzidos com cimento Secar 71, CPII E 32 e CPV ARI, considerando uma ordem decrescente de eficiência.

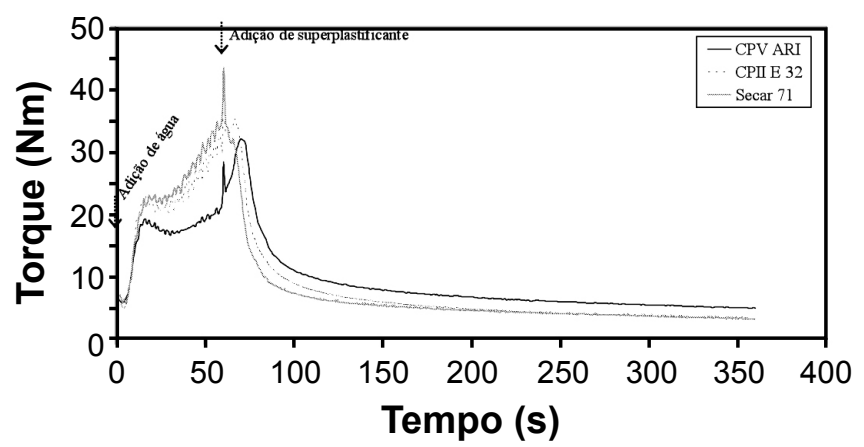

Figura 4: Curva de mistura dos concretos produzidos com diferentes cimentos.

[Figure 4: Mixing curve of the concretes produced with different cements.]

Tabela IV- Área sob a curva de mistura dos concretos produzidos com diferentes cimentos.

[Table IV - Area under the mixing curve for the concretes produced with different cements.]

\begin{tabular}{cc}
\hline Cimento & Área (Nm.s) \\
\hline CPV ARI & 3.522 \\
CPII E 32 & 3.283 \\
Secar 71 & 3.192 \\
\hline
\end{tabular}

\section{Curvas de cisalhamento}

Para a construção das curvas de cisalhamento, a velocidade foi considerada em rotações por segundo (rps) para que o parâmetro relacionado com a viscosidade plástica (viscosidade de torque $-h$ ), expresso em Nm.s, fosse determinado diretamente a partir da equação da reta de ajuste ao modelo.

A partir das curvas de cisalhamento (Figs. 5, 6 e 7),

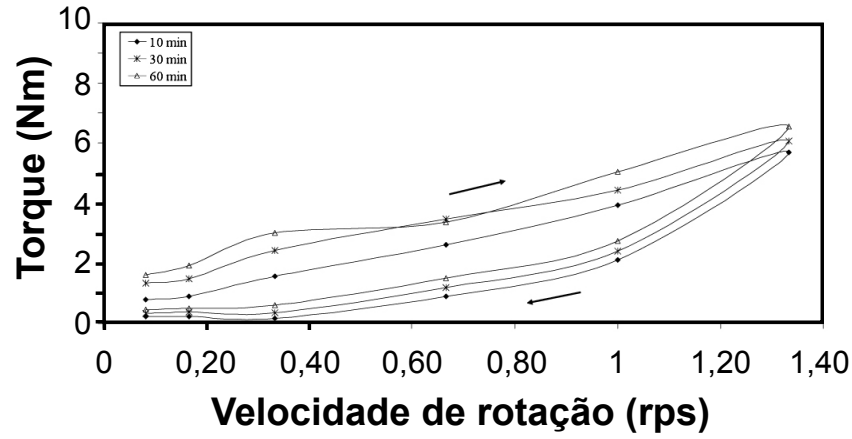

Figura 5: Curvas de cisalhamento do concreto produzido com CPV ARI. Obs.: As setas indicam o sentido de aplicação da velocidade de cisalhamento.

[Figure 5: Flow curves of the concrete produced with CPV ARI. Obs.: The arrows indicate the up and down curves, respectively.]

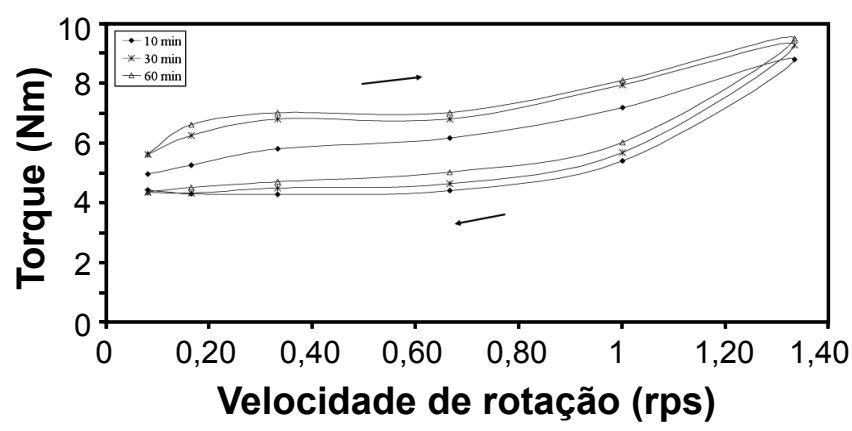

Figura 6: Curvas de cisalhamento do concreto produzido com CPII E 32. Obs.: As setas indicam o sentido de aplicação da velocidade de cisalhamento.

[Figure 6: Flow curves of the concrete produced with CPII E 32. Obs.: The arrows indicate the up and down curves, respectively.]

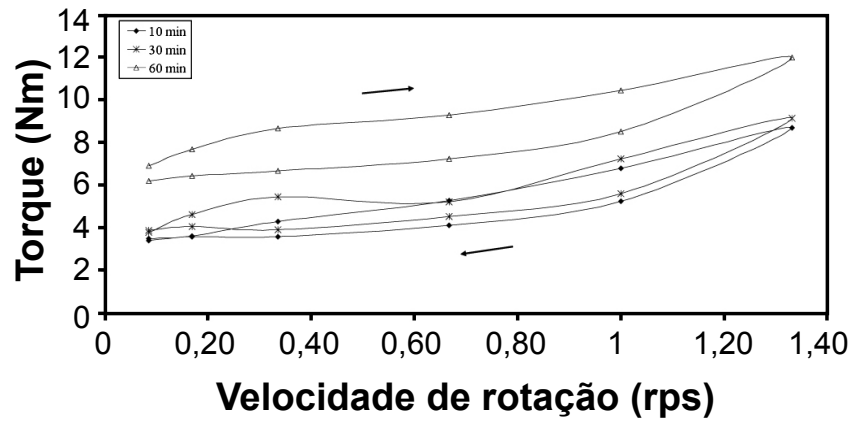

Figura 7: Curva de cisalhamento do concreto produzido com Secar 71. Obs.: As setas indicam o sentido de aplicação da velocidade de cisalhamento.

[Figure 7: Flow curve of the concrete produced with Secar 71. Obs: The arrows indicate the up and down curves, respectively.]

verifica-se que a parte ascendente e a parte descendente não coincidem, resultando em uma área de histerese. A formação dessa histerese indica que o misturador utilizado não foi capaz de fornecer energia suficiente para quebrar os aglomerados presentes na mistura; assim, um processo de mistura mais eficiente está relacionado com uma menor área de histerese. Além disso, a não coincidência das partes ascendente e descendente da curva de cisalhamento evidencia o comportamento pseudoplástico dos concretos, 
que foi verificado independentemente do tipo de cimento usado na sua composição.

Os valores das áreas de histerese geradas (Tabela V) variam entre os concretos produzidos com diferentes tipos de cimento. As áreas calculadas confirmam a eficiência de mistura, ou seja, a ordem obtida pelo cálculo da área sob a curva de mistura se repetiu quando a análise foi feita a partir do cálculo da área de histerese resultante da curva de cisalhamento (Secar $71>$ CPII E $32>$ CPV ARI, considerando a ordem decrescente de eficiência).

Tabela V - Área de histerese das curvas de cisalhamento dos concretos estudados - unidade: Nm.rps.

[Table V - Hysteresis area for the concretes' flow curves unity: Nm.rps.]

\begin{tabular}{cccc}
\hline & \multicolumn{3}{c}{ Tempo de medida (min) } \\
Cimento & 10 & 30 & 60 \\
\hline CPV ARI & 1,95 & 2,50 & 2,62 \\
CPII E 32 & 1,68 & 2,33 & 2,24 \\
Secar 71 & 1,08 & 1,24 & 2,01 \\
\hline
\end{tabular}

Um fato a ser destacado é o comportamento das curvas de cisalhamento ao longo do tempo. Enquanto as curvas obtidas para ambos os cimentos Portland são praticamente justapostas para todos os tempos de medida, verifica-se um deslocamento da curva de cisalhamento medida aos $60 \mathrm{~min}$ - com relação às curvas medidas aos 10 e 30 min de ensaio para o cimento aluminoso. Isso pode estar relacionado com o início do processo de pega desse cimento antes do fim do ensaio, o que indicaria uma tendência contrária ao resultado do tempo de pega medido com o auxílio da agulha de Vicat e apresentado na Tabela II. Assim, para melhor elucidar estes aspectos usou-se também a técnica da condutividade iônica, cujos resultados são apresentados a seguir (Fig. 8).

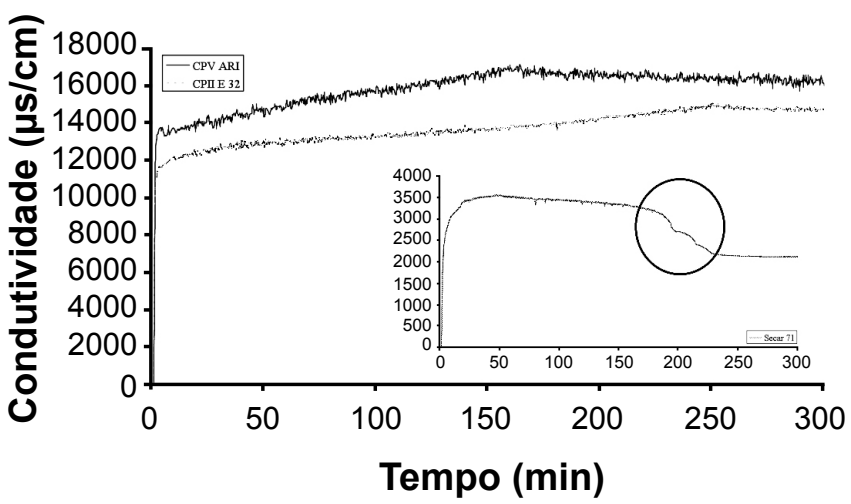

Figura 8: Curvas de condutividade iônica em função do tempo das suspensões aquosas dos três cimentos utilizados na produção dos concretos estudados, com destaque para a queda de condutividade apresentada para o cimento aluminoso.

[Figure 8: Ionic conductivity curves as a function of time for aqueous suspensions for the cements used in the production of the concretes analyzed, highlighting the conductivity decrease for the calcium aluminate cement.]
O processo de hidratação das partículas de cimento em água envolve três períodos distintos: dissolução de íons, nucleação e precipitação de fases hidratadas. Assim que as partículas de cimento entram em contato com a água, iniciase a dissociação das fases anidras e, com isso, a liberação de íons no meio líquido. O processo de dissolução ocorre até que a concentração dos íons em solução alcance certo nível de saturação, promovendo a precipitação dos hidratos por meio de mecanismos de nucleação e crescimento. A precipitação dos primeiros produtos da hidratação diminui a concentração de íons em solução, favorecendo a dissociação das fases anidras. Isso resulta em um processo contínuo de dissolução-precipitação até que a maioria (ou toda) da fase anidra tenha reagido. Desde que a nucleação heterogênea na superfície das partículas seja favorecida, os hidratos precipitados tendem a formar fortes ligações entre as partículas vizinhas, promovendo a pega e o endurecimento do concreto [21].

Com o aumento da condutividade iônica, o potencial superficial das partículas de cimento tende a diminuir, resultando na aglomeração das partículas e, com isso, no endurecimento do sistema. Os cimentos Portland estudados apresentaram valores de condutividade iônica muito superiores ao medido para o cimento aluminoso (Fig. 8), o que justifica o menor tempo de início de pega medido pelo ensaio de Vicat (Tabela II). Por outro lado, o cimento aluminoso não apresenta um aumento inicial da força iônica do meio tão acentuado como o cimento Portland, refletindo em um tempo de início de pega superior.

Porém, para o cimento aluminoso, verificou-se uma discordância entre o tempo de fim de pega medido com o método usual da agulha de Vicat (Tabela II) e os resultados obtidos com o ensaio de condutividade iônica e reometria. Aparentemente, a reometria e a condutividade iônica estariam indicando um fim de pega mais breve desse cimento, enquanto a agulha de Vicat apontaria em outra direção. Tal efeito despertou interesse dos autores e será assunto de um estudo complementar, visto que estas técnicas podem estar indicando fenômenos distintos do processo de dissoluçãoprecipitação que os cimentos aluminosos estão sujeitos.

\section{Caracterização reológica}

Para a identificação do comportamento reológico das misturas de concreto, os ajustes foram feitos tanto na parte ascendente quanto na parte descendente da curva de cisalhamento. Porém, a consideração da parte ascendente se mostrou mais adequada (maiores coeficientes de correlação), além de corresponder ao período em que a tensão de escoamento deve ser excedida para que o material inicie seu escoamento.

A partir das curvas de cisalhamento obtidas (Figs. 9, 10 e 11), verificou-se que, independente do tipo de cimento adotado na produção dos concretos, os comportamentos reológicos de todas as misturas estudadas se ajustaram melhor ao modelo binghamiano, ou seja, o ajuste da parte ascendente da curva de cisalhamento resultou nos maiores 


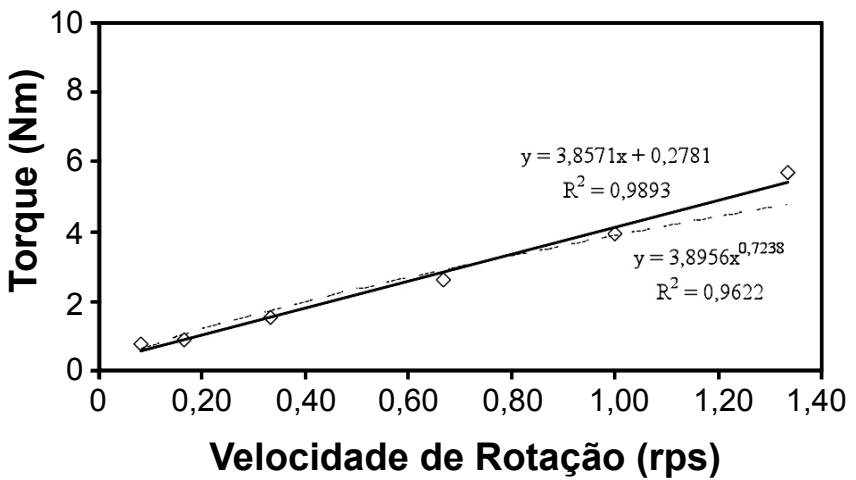

$\diamond$ Dados $\quad-$ - Leis das potências —Bingham

Figura 9: Parte ascendente da curva de cisalhamento do concreto produzido com CPV ARI.

[Figure 9: Shearing upward plot for the concrete containing CPV ARI.]

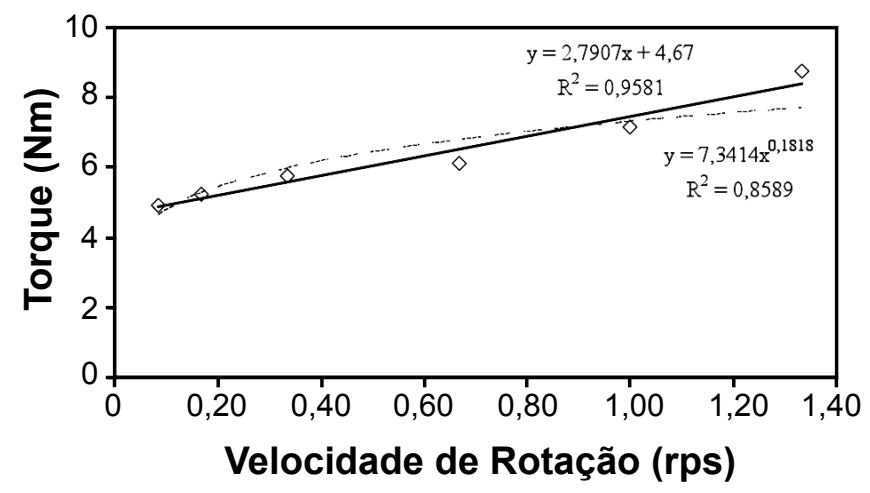

$\diamond$ Dados $\quad-$ Leis das potências _-Bingham

Figura 10: Parte ascendente da curva de cisalhamento do concreto produzido com CPII E 32.

[Figure 10: Shearing upward plot for the concrete containing CPII E 32.]

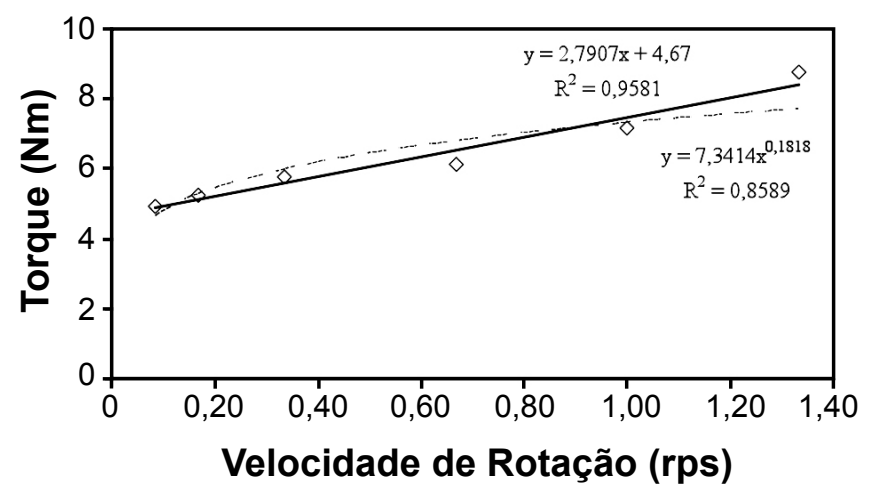

$\diamond$ Dados -- Leis das potências -Bingham

Figura 11: Parte ascendente da curva de cisalhamento do concreto produzido com Secar 71.

[Figure 11: Shearing upward plot for the concrete containing Secar71.] coeficientes de correlação entre a curva e a reta constitutiva do modelo. Esse comportamento é amplamente observado para as misturas de concreto de alto desempenho encontradas na literatura [22]. Assim, sendo o comportamento dos concretos estudados semelhantes ao de um fluido plástico ou binghamiano (equação B), dois parâmetros reológicos são necessários para sua caracterização: a tensão de escoamento $\left(\tau_{o}\right)[\mathrm{Pa}]$ e a viscosidade plástica $(\mu)[\mathrm{Pa} . \mathrm{s}]$. Porém, em função da heterogeneidade do concreto, esses parâmetros são normalmente expressos em unidades de torque, sendo a relação entre o torque $(\mathrm{T})[\mathrm{Nm}]$ e a velocidade de rotação (N) [rps] dada segundo a equação $\mathrm{C}$.

$$
\begin{aligned}
& \tau=\tau_{0}+\mu \dot{\gamma} \\
& \mathrm{T}=\mathrm{g}+\mathrm{h}^{*} \mathrm{~N}
\end{aligned}
$$

onde $\tau$ é a tensão de cisalhamento [Pa] e $\dot{\gamma}$ é a taxa de cisalhamento $\left[\mathrm{s}^{-1}\right]$, na equação $\mathrm{B}, g$ é o torque de escoamento [Nm] e $h$ é a viscosidade de torque [Nm.s] na equação $\mathrm{C}$, e consideradas análogas à tensão de escoamento e a viscosidade plástica, respectivamente [23]. Assim, os valores dos parâmetros reológicos que caracterizam os comportamentos dos concretos estudados são apresentados na Tabela VI em unidades de torque.

Tabela VI - Valores dos parâmetros reológicos considerandose a parte ascendente da curva de cisalhamento e o comportamento binghamiano.

[Table VI - Values of the rheological parameters considering

\begin{tabular}{|c|c|c|c|c|c|c|}
\hline \multirow{3}{*}{ Cimento } & \multirow{2}{*}{\multicolumn{3}{|c|}{$\begin{array}{c}\text { Torque de } \\
\text { escoamento } \\
{[g(\mathrm{Nm})]} \\
\text { Tempo de } \\
\text { medida (min) }\end{array}$}} & \multicolumn{3}{|c|}{$\begin{array}{c}\text { Viscosidade } \\
\text { de torque } \\
{[h(\mathrm{Nm} . \mathrm{s})]}\end{array}$} \\
\hline & & & & \multicolumn{3}{|c|}{$\begin{array}{l}\text { Tempo de medida } \\
\text { (min) }\end{array}$} \\
\hline & 10 & 30 & 60 & 10 & 30 & 60 \\
\hline CPV ARI & 0,28 & 1,01 & 1,34 & 3,86 & 3,68 & 3,76 \\
\hline CPII E 32 & 4,67 & 5,57 & 5,76 & 2,79 & 2,54 & 2,54 \\
\hline Secar 71 & 2,93 & 3,68 & 6,95 & 4,08 & 3,75 & 3,69 \\
\hline
\end{tabular}
upward part of the flow curve and the Bingham behavior.]

Como a aplicação dos concretos não se dá imediatamente após a mistura, é preciso conhecer seu comportamento durante o intervalo de tempo necessário para sua aplicação. Assim, as propriedades reológicas dos concretos foram acompanhadas ao longo do tempo, com as amostras sendo submetidas a ciclos de cisalhamento 10, 30 e 60 min após o contato águacimento. A partir dos valores obtidos (Tabela VI), verifica-se que o torque de escoamento aumentou ao longo do tempo, enquanto a viscosidade permaneceu praticamente constante. Isso quer dizer que, uma vez que a tensão de escoamento tenha sido excedida, sua resistência ao escoamento permanece praticamente a mesma para as taxas de cisalhamento aplicadas, dentro do intervalo de tempo avaliado. 
O aumento do torque de escoamento reflete o processo de pega e endurecimento do material; porém, não a evolução da viscosidade. Como as amostras de concreto permanecem em repouso entre os consecutivos ensaios reológicos, a exigência de torque para as baixas velocidades de rotação aumenta mais do que para as velocidades mais altas, provavelmente devido à aglomeração das partículas, à geração dos produtos da hidratação e ao esgotamento das moléculas de superplastificante no processo químico de dispersão. Isso resulta em uma redução da inclinação da curva de cisalhamento, o que pode explicar porque a viscosidade não aumenta com o tempo, tendendo a diminuir ligeiramente em alguns casos [24].

\section{Curvas de endurecimento}

As curvas de endurecimento, avaliadas sob cisalhamento contínuo, para os concretos estudados são apresentadas na Fig. 12. Os concretos produzidos com ambos os cimentos Portland (CPV ARI e CPII E 32) apresentaram a mesma tendência de pega e endurecimento, o que ocorreu de maneira contínua e gradual ao longo do tempo, diferenciando apenas nos valores de torque medidos no processo. Porém, para o concreto produzido com cimento aluminoso (Secar 71), verificou-se uma perda acentuada da trabalhabilidade logo na primeira hora de ensaio. Isso pode estar relacionado com o rápido enrijecimento da mistura a fim de se atingir altas resistências nas primeiras horas da hidratação, conforme observado nos ensaios de condutividade iônica realizados em suspensões de cimento puro (Fig. 8).

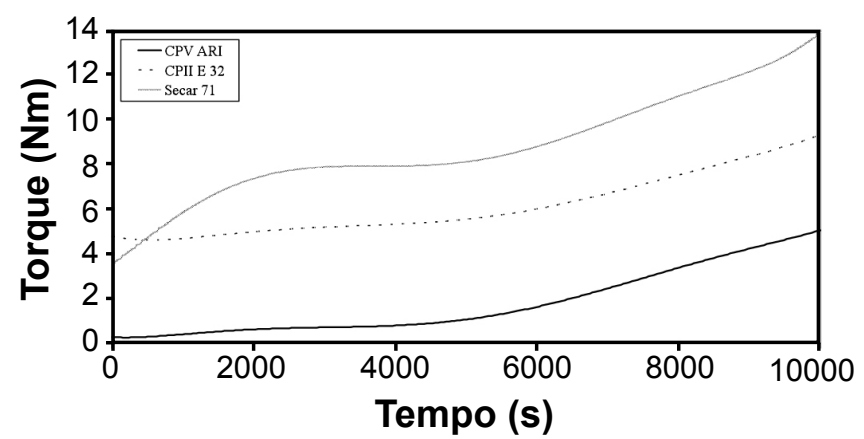

Figura 12: Curvas de endurecimento dos concretos estudados. [Figure 12: Hardening curves of the studied concretes.]

\section{Propriedades do concreto no estado endurecido}

\section{Porosidade aparente}

A porosidade inicial é determinada pela relação água/ cimento da mistura. Porém, uma vez fixada a quantidade de água, é o processo de hidratação que determina a extensão do preenchimento e redistribuição de poros [12]. A evolução da porosidade aparente dos concretos estudados, avaliada ao longo do tempo, é apresentada na Fig. 13. Com exceção da idade de 1 dia, os concretos produzidos com cimento Portland apresentaram porosidades semelhantes e bastante reduzidas, independente do tipo de cimento utilizado (CPV ARI ou CPII E 32). A baixa porosidade aparente desses materiais está relacionada com a baixa relação água/ aglomerante $(0,35)$ considerada na sua produção. Assim, parte dos materiais aglomerantes não-hidratados pôde contribuir com o efeito fíler proporcionado pela adição mineral (sílica ativa), melhorando o empacotamento das partículas e, com isso, resultando em matrizes mais densas em idades avançadas (28 dias). No caso do concreto produzido com Secar 71, a porosidade aparente reduziu com o decorrer do tempo, atingindo valores próximos aos dos concretos de cimento Portland. Porém, aos 10 dias de idade, verificou-se uma inversão dessa tendência, ou seja, a porosidade aumentou. Esse aumento está relacionado com o mecanismo de conversão das fases hidratadas do cimento aluminoso. Durante o processo de hidratação desse cimento, os produtos formados $\left(\mathrm{CAH}_{10} \mathrm{e} \mathrm{C}_{3} \mathrm{AH}_{8}\right)$ são quimicamente instáveis e se transformam em uma fase mais estável e de maior densidade $\left(\mathrm{C}_{3} \mathrm{AH}_{6}\right)$. Como conseqüência dessa conversão, a pasta endurecida de cimento aluminoso pode apresentar uma redução de volume de sólidos de mais de $50 \%$, o que causa aumento na porosidade e perda de resistência $[9,25]$. Tal efeito é ainda mais significativo se os concretos forem processados durante um período que envolve grande oscilação da temperatura ambiente.

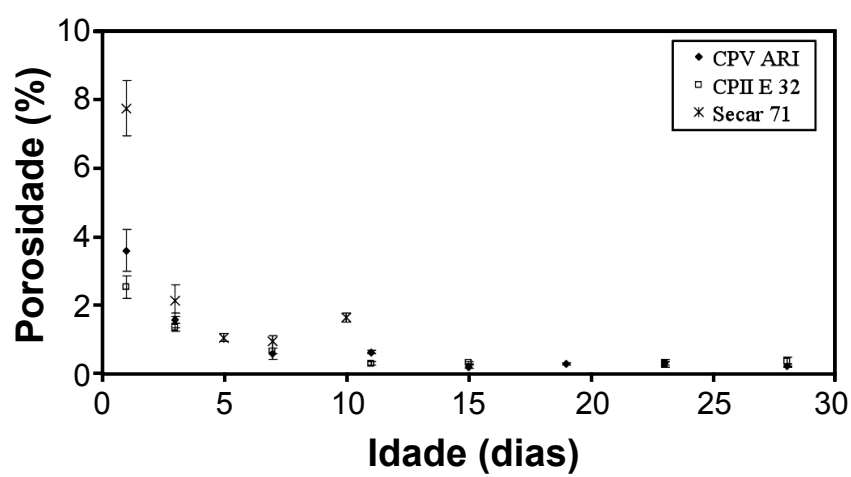

Figura 13: Evolução da porosidade aparente dos concretos ao longo do tempo.

[Figure 13: Evolution of the concretes' apparent porosity with the time.]

\section{Resistência mecânica}

O desenvolvimento do comportamento mecânico dos concretos estudados ao longo do tempo, expresso em termos de resistência à compressão uniaxial, resistência à tração por compressão diametral e resistência à flexão em 3 pontos, é apresentado nas Figs. 14, 15 e 16, respectivamente. No caso do cimento Portland, o concreto produzido com CPV ARI apresenta maiores resistências do que os concretos produzidos com CPII E 32 devido ao seu maior teor de $\mathrm{C}_{3} \mathrm{~S}$ (co-responsável pelo desenvolvimento da resistência) e seu menor tamanho de partículas (maior área superficial). A diferença entre as resistências medidas se mantém até os 28 dias. O comportamento mecânico do concreto de cimento 


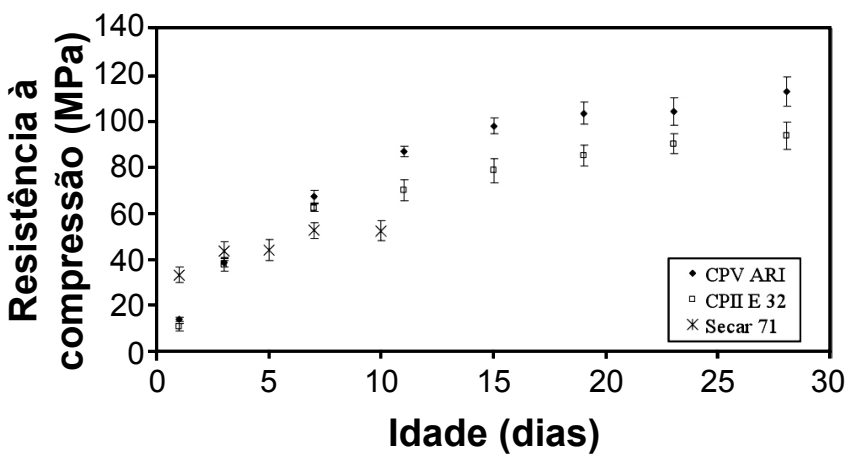

Figura 14: Evolução da resistência à compressão uniaxial dos concretos ao longo do tempo.

[Figure 14: Evolution of the concretes' compressive strength with the time.]

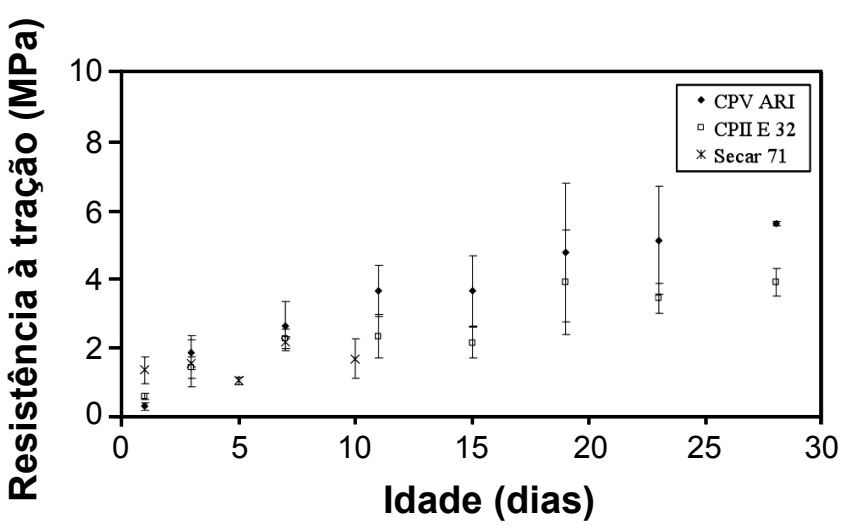

Figura 15: Evolução da resistência à tração por compressão diametral dos concretos ao longo do tempo.

[Figure 15: Evolution of the concretes' splitting tensile strength with the time.]

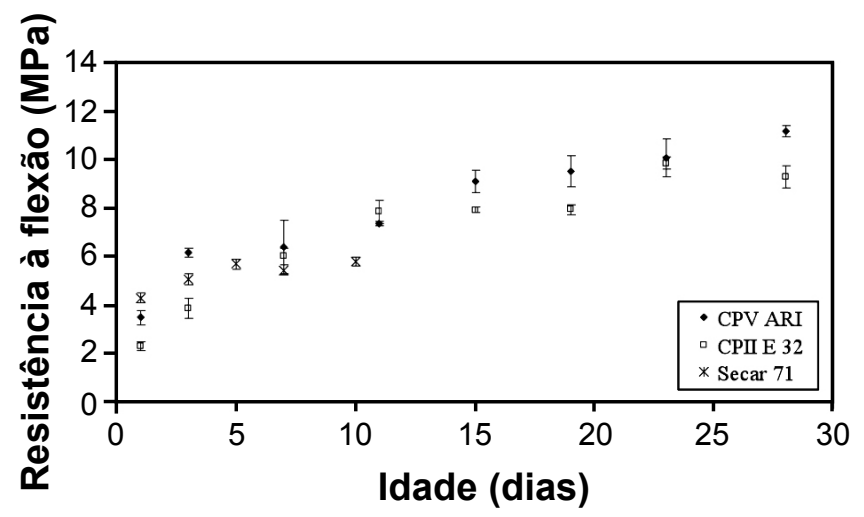

Figura 16: Evolução da resistência à flexão em 3 pontos dos concretos ao longo do tempo.

[Figure 16: Evolution of the concretes' 3 point bending strength with the time.]

aluminoso pode ser descrito por uma alta resistência inicial, seguida por uma perda dessa resistência com o decorrer do tempo. A alta resistência inicial é uma característica do cimento aluminoso, uma vez que cerca de $80 \%$ da sua resistência final pode ser obtida em $24 \mathrm{~h}$. A perda de resistência ao longo do tempo está relacionada com o mecanismo de conversão das fases hidratadas do cimento descrito anteriormente. Esse comportamento do concreto de cimento aluminoso limita sua utilização em aplicações estruturais, a menos que o corpo seja aquecido e autoclavado e as fases estáveis sejam obtidas antes da aplicação do material em construções civis.

\section{Módulo de elasticidade}

Os valores dos módulos de elasticidade usados nos cálculos estruturais de estruturas de concreto são normalmente estimados a partir de expressões empíricas que pressupõem dependência direta entre o módulo de elasticidade, a resistência e a densidade do concreto. Em materiais homogêneos realmente existe essa relação, porém, em materiais heterogêneos e multifásicos como o concreto, a fração volumétrica, a densidade e o módulo de elasticidade dos principais constituintes (agregados e matriz), bem como as características da zona de transição é que determinam o comportamento elástico do compósito. Para o concreto, a relação direta entre a resistência e o módulo de elasticidade provém do fato de que ambos são influenciados pela porosidade e pelas fases constituintes, embora não no mesmo grau [9].

As evoluções dos módulos de elasticidade estático e dinâmico ao longo do tempo são apresentadas, respectivamente, nas Figs. 17 e 18 e a correlação entre eles na Fig. 19. A partir dos gráficos, verifica-se que ambos os módulos de elasticidade dos concretos produzidos com cimento Portland apresentaram um aumento contínuo ao longo do tempo, além de uma boa correlação entre os valores medidos (coeficientes de correlação sempre maior que 0,90 ). Porém, o concreto produzido com cimento aluminoso, em função do aumento da porosidade, apresentou perda do módulo de elasticidade estático, enquanto o módulo dinâmico - que corresponde a uma deformação instantânea muito pequena - não foi influenciado pelo aumento da porosidade. Assim, o comportamento diferenciado entre os dois módulos de elasticidade medidos não permitiu estabelecer uma boa

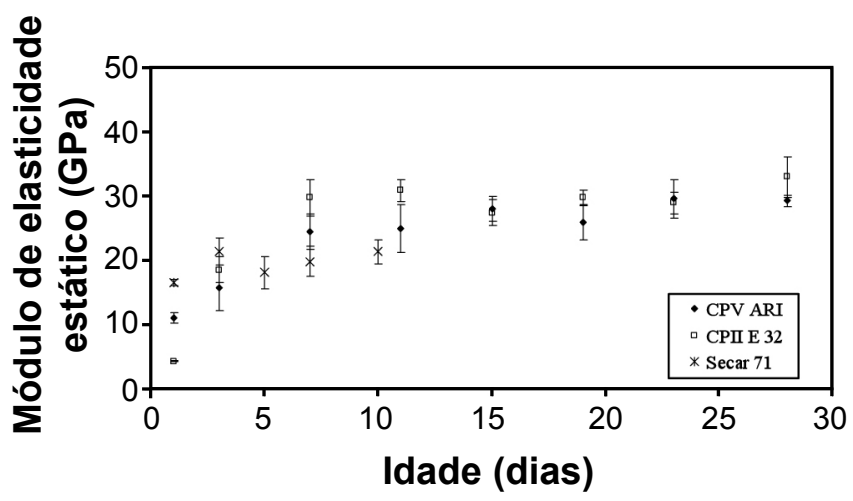

Figura 17: Evolução do módulo de elasticidade estático dos concretos ao longo do tempo.

[Figure 17: Evolution of the concretes'static Young's modulus with the time.] 


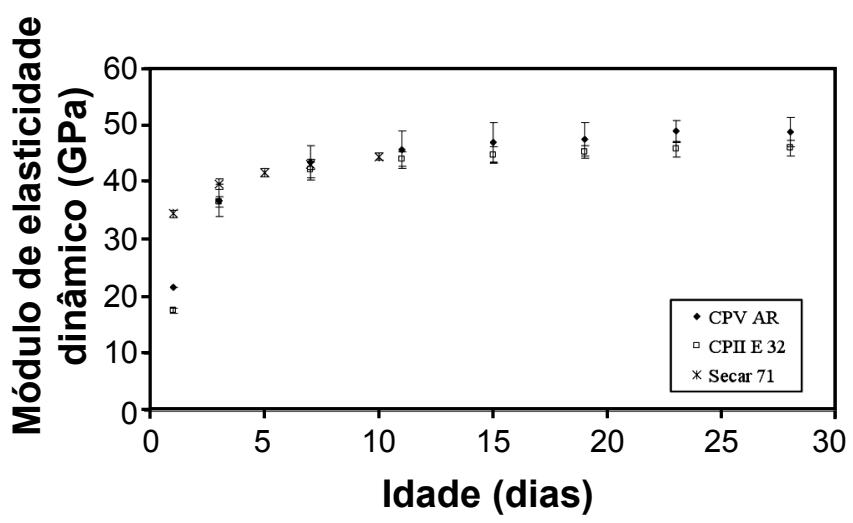

Figura 18: Evolução do módulo de elasticidade dinâmico dos concretos ao longo do tempo.

[Figure 18: Evolution of the concretes' dynamic Young's modulus with the time.]

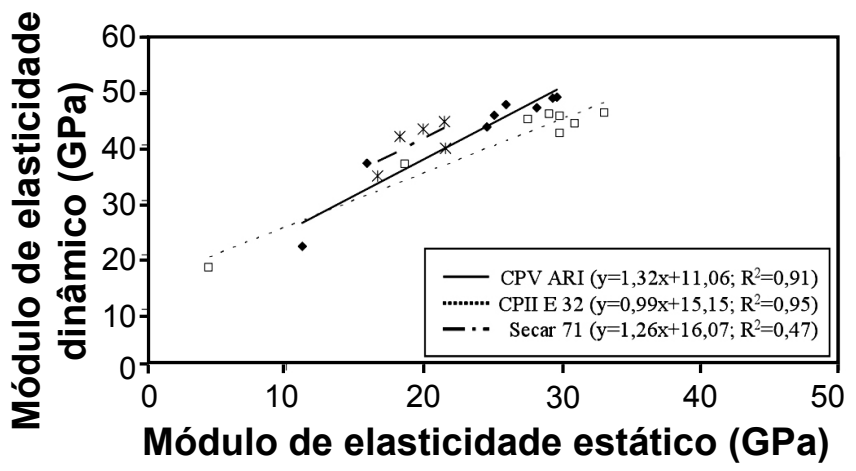

Figura 19: Correlação entre os módulos de elasticidade estático e dinâmico dos concretos.

[Figure 19: Correlation between static and dynamic Young's modulus for the concretes.]

correlação entre eles (coeficiente de correlação menor que $0,50)$. De acordo com a literatura, o módulo de elasticidade dinâmico é indicado como sendo maior que o módulo de elasticidade estático em torno de $20 \%, 30 \%$ e $40 \%$ para concretos de alta, média e baixa resistência, respectivamente [9]. A partir dos resultados obtidos, as relações entre os módulos recomendadas na literatura não foram obedecidas, porém o módulo de elasticidade dinâmico medido foi sempre superior que o módulo estático.

\section{CONCLUSÕES}

Mantendo-se os mesmos materiais constituintes da mistura e o mesmo coeficiente de empacotamento das partículas, uma mudança apenas do tipo de cimento implicou em variações no teor ótimo de aditivo necessário para se obter concretos auto-adensáveis. A variação do tipo de cimento resultou em diferentes eficiências de mistura, determinadas pela área sob a curva de mistura e comprovadas pela área de histerese gerada nas curvas de cisalhamento dos concretos. A natureza reológica foi identificada como sendo semelhante a um fluido plástico ou Binghamiano, independente do tipo de cimento usado na composição do concreto. Os parâmetros reológicos obtidos foram diferentes entre os concretos estudados, indicando comportamentos reológicos distintos. Ao longo do tempo, verificou-se um aumento da tensão de escoamento, enquanto a viscosidade permaneceu praticamente constante. Os processos de pega e endurecimento dos concretos medidos sob cisalhamento contínuo foram distintos para os cimentos Portland e aluminoso. Os concretos de cimento Portland apresentaram um processo de pega e endurecimento contínuo e gradual ao longo do tempo, enquanto o concreto produzido com cimento aluminoso apresentou uma perda de trabalhabilidade acentuada logo na primeira hora de ensaio. Essa diferença pode estar relacionada com a velocidade da hidratação dos cimentos, que é muito mais rápida para o cimento aluminoso do que para ambos os cimentos Portland, conforme observado no ensaio de condutividade iônica. No caso do cimento Portland, o concreto produzido com CPV ARI apresentou maiores resistências do que o concreto produzido com CPII E 32, devido ao seu maior teor de $\mathrm{C}_{3} \mathrm{~S}$ e superior área superficial, sendo que esta diferença se manteve até os 28 dias de idade. $\mathrm{O}$ concreto produzido com cimento aluminoso apresentou uma alta resistência inicial, porém, ao longo do tempo, verificou-se uma perda dessa resistência, sendo esta correlacionada com o mecanismo de conversão das fases hidratadas desse cimento (para inibir as transformações de fase do cimento aluminoso, que prejudicam seu desempenho mecânico, seria necessário um tratamento em autoclave e sob temperatura de aproximadamente $80{ }^{\circ} \mathrm{C}$ ). Comparando todas as propriedades medidas - tanto no estado fresco, quanto no estado endurecido - verifica-se que os concretos produzidos com os dois cimentos Portland considerados apresentaram desempenhos superiores ao do concreto produzido com cimento aluminoso, sendo o cimento Portland de alta resistência inicial ainda mais eficiente que o cimento Portland composto para a produção de misturas de alto desempenho e até os 28 dias de idade.

\section{AGRADECIMENTOS}

Ao Conselho Nacional de Desenvolvimento Científico e Tecnológico, CNPq, pela bolsa de estudo, e às Empresas Holcim Brasil S. A., Elkem Materials South America Ltda., Basf Construction Chemicals Brasil e Mineração Jundu Ltda., pela doação dos materiais utilizados na pesquisa. O apoio da Dra. I. R. Oliveira nos ensaios de condutividade iônica também é reconhecido.

\section{REFERÊNCIAS}

[1] P.-C. Aïtcin, "Cements of yesterday and today; concrete of tomorrow", Cement Concrete Res. 30, 9 (2000) 13491359 .

[2] P.-C. Aïtcin, "Concreto de alto desempenho", Trad.: G. G. Serra, PINI, S. Paulo, SP (2000).

[3] J. B. L. Liborio, A. L. Castro, F. G. Silva, V. M. Silva, Proc. IV High Performance Concrete Structures - IV ACI/ CANMET Conf. Quality of Concrete Structures and Recent 
Advances in Concrete Materials and Testing, Olinda, PE (2005) cdrom.

[4] H. Vikan, H. Justnes, F. Winnefeld, R. Figi, "Correlating cement characteristics with rheology of paste", Cement Concrete Res. 37, 11 (2007) 1502-1511.

[5] T. Okamura, H. Harada, M. Daimon, "Influence of calcium sulfate in belite-rich cement on the change in fluidity of mortar with time", Cement Concrete Res. 28, 9 (1998) 1297-1308.

[6] P.-C. Aïtcin, C. Jolicoeur, J. G. MacGregor, "Superplasticizers: how they work and why they occasionally don't”, Concrete Int. 16, 5 (1994) 45-52.

[7] D. Bonen, S. L. Sarkar, "The superplasticizer adsorption capacity of cement pastes, pore solution composition, and parameters affecting flow loss", Cement Concrete Res. 25, 7 (1995) 1423-1434.

[8] S. Erdogdu, "Compatibility of superplasticizers with cements different in composition", Cement Concrete Res. 30, 5 (2000) 767-773.

[9] P. K. Mehta, P. J. M. Monteiro, "Concreto: estrutura, propriedades e materiais”, PINI, S. Paulo, SP (1994).

[10] D. P. Bentz, E. J. Garboczi, C. J. Haecker, O. M. Jensen, "Effects of cement particle size distribution on performance properties of Portland cement-based materials", Cement Concrete Res. 29, 10 (1999) 1663-1671.

[11] W. Aiqin, Z. Chengzhi, Z. Ningsheng, "Study of the influence of the particle size distribution on the properties of cement", Cement Concrete Res. 27, 5 (1997) 685-695.

[12] I. O. Yaman, H. M. Aktan, N. Hearn, "Active and nonactive porosity in concrete - Part I: experimental evidence", Mater. Structures 35, 2 (2002) 102-109.

[13] M. R. Jones, L. Zheng, M. D. Newlands, "Comparison of particle packing models for proportioning concrete constituents for minimum voids ratio", Mater. Structures 35, 5 (2002) 301-309.

[14] American Society for Testing and Materials, ASTM C 830: "Apparent porosity, liquid absorption, apparent specific gravity, and bulk density of refractory shapes by vacuum pressure" (1993).

[15] Associação Brasileira de Normas Técnicas, NBR 5739:

"Concreto - ensaio de compressão de corpos-de-prova cilíndricos", Rio de Janeiro, RJ (1994).

[16] American Society for Testing and Materials, ASTM C 496: "Splitting tensile strength of cylindrical concrete specimens" (1990).

[17] American Society for Testing and Materials, ASTM C 133: "Cold crushing strength and modulus of rupture of refractories" (1994).

[18] Associação Brasileira de Normas Técnicas, NBR 8522: "Concreto - determinação dos módulos estáticos de elasticidade e de deformação e da curva tensão-deformação", Rio de Janeiro, RJ (2003).

[19] American Society for Testing and Materials. ASTM C 1259: "Dynamic Young's modulus, shear modulus, and Poisson's ratio for advanced ceramics by impulse excitation of vibration" (1994).

[20] H. Beitzel, Y. Charonnat, M. Beitzel, "Assessment and classification of performance mixers", Mater. Structures 36, 4 (2003) 250-264.

[21] I. R. Oliveira, F. S. Ortega, L. R. M. Bittencourt, V. C. Pandolfelli, "Hydration kinetics of hydratable alumina and calcium aluminate cement, J. Techn. Assoc. Refract." 28, 3 (2008) 172.

[22] G. H. Tattersall, P. F. G. Banfill, "The rheology of fresh concrete", Pitman, London, UK (1983).

[23] T. Yen, C.-W. Tang, C.-S. Chang, K.-H. Chen, "Flow behavior of high strength high-performance concrete", Cement Concrete Comp. 21, 5-6 (1999) 413-424.

[24] M. Nehdi, S. Mindess, P.-C. Aïtcin, "Rheology of highperformance concrete: effect of ultrafine particles", Cement Concrete Res. 28, 5 (1998) 687-697.

[25] A. M. Neville, "Propriedades do concreto", Trad.: Salvador E. Giammusso, 2a Ed., PINI, S. Paulo, SP (1997).

[26] A. L. Castro, V. C. Pandolfelli, "Artigo revisão Conceitos de dispersão e empacotamento de partículas para a produção de concretos especiais aplicados na construção civil", Cerâmica 55, 333 (2009) 18.

[27] A. L. Castro, J. B. L. Liborio, V. C. Pandolfelli, "Desempenho de concretos avançados para a construção civil formulados a partir do método de dosagem computacional", Cerâmica 55, 335 (2009) 233.

(Rec. 21/06/2008, Ac. 13/12/2008) 